\title{
Novel Dyes Based on Extended Fulvene Motifs: Synthesis via Redox Reactions of Naphthoquinones with Donor-Acceptor Cyclopropanes and Their Spectroelectrochemical Behavior
}

\author{
Alexander Lücht, ${ }^{[a]}$ Sebastian Sobottka, ${ }^{[b]}$ Lukas J. Patalag, ${ }^{[a]}$ Peter G. Jones, ${ }^{[c]}$ Hans-Ulrich Reissig, ${ }^{[\mathrm{d}]}$ \\ Biprajit Sarkar, ${ }^{*[b]}$ and Daniel B. Werz ${ }^{*[a]}$
}

\begin{abstract}
Novel dyes based on extended fulvene motifs are reported. The carbon skeleton was generated by a catalyzed addition of donoracceptor cyclopropanes to naphthoquinone. The hydroxy group at the central ring of the tricyclic fulvene motif was converted into the triflate which efficiently reacted with a broad range of nucleophiles resulting in substitution providing new derivatives. The aforementioned synthetic versatility allowed us to investigate the absorption, electrochemical and UV-Vis-NIR spectroelectrochemical properties of these dyes as a function of the substituents. We have shown that the dyes participate in reductive electrochemistry, the reversibility of which can be improved by a judicious selection of the substituents. Additionally, first signs of NIR electrochromism is also presented, opening new avenues for the future investigations of such dyes.
\end{abstract}

investigating the redox behavior of organic dyes, their redoxstability and possible electrochromism. ${ }^{[3]}$

Besides these physical parameters of dyes it is of utmost importance that their preparation is simple and only few steps are required. Almost all type of organic dyes are structurally based on extended $\pi$-systems resulting in close HOMO-LUMO gaps. In a first-order approximation the complementary color to the absorbed wavelength is the visible color of the dye. Thus, simple molecular orbital considerations suggest how color deepening can be achieved: To decrease the HOMO-LUMO gap one might either raise the HOMO level or decrease the LUMO level or do both. In other words, an adequate substitution pattern on the $\pi$-system, in particular with donor and acceptor groups at proper position, should lead to a color deepening.

\section{Introduction}

There is a continuous interest in the development of organic dyes whose colors can be tuned by judicious selection of the chromophore structure. Apart from the color itself, other properties that are attractive for such molecules are their redoxstability, which might then render such dyes electrochromic either in the visible or in the NIR region of the electromagnetic spectrum. In addition to the color considerations, ${ }^{[1]}$ such redox-active organic molecules might also find use as mediators in redox catalysis. ${ }^{[2]}$ (Spectro)electrochemistry is the method of choice for

[a] M. Sc. A. Lücht, Dr. L. J. Patalag, Prof. Dr. D. B. Werz Technische Universität Braunschweig

Institut für Organische Chemie

Hagenring 30, 38106 Braunschweig (Germany)

E-mail: d.werz@tu-braunschweig.de

Homepage: http://www.werzlab.de

[b] M. Sc. S. Sobottka, Prof. Dr. B. Sarkar

Freie Universität Berlin

Institut für Chemie und Biochemie, Anorganische Chemie

Fabeckstraße 34-36, 14195 Berlin (Germany)

E-mail: biprajit.sarkar@fu-berlin.de

[c] Prof. Dr. P. G. Jones

Technische Universität Braunschweig

Institut für Anorganische und Analytische Chemie

Hagenring 30, 38106 Braunschweig (Germany)

[d] Prof. Dr. H.-U. Reissig

Freie Universität Berlin

Institut für Chemie und Biochemie

Takustraße 3, 14195 Berlin (Germany)

Supporting information for this article is given via a link at the end of the document.

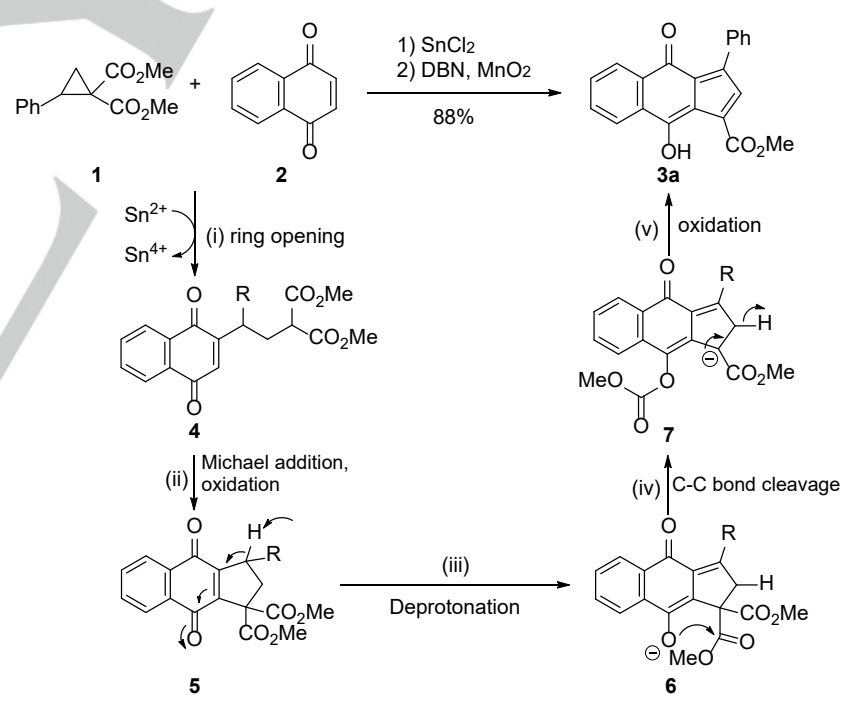

Scheme 1. Synthesis of tricyclic compounds 3 with extended fulvene motif by catalyzed addition of donor-acceptor cyclopropanes $\mathbf{1}$ to naphthoquinones $\mathbf{2}$

Recently, we published an unprecedented access to a molecular scaffold with a unique conjugated $\pi$-system including an extended fulvene motif. ${ }^{[4]}$ Fulvenes are well-known isomers to benzene with a five-membered substructure and an exocyclic double bond. ${ }^{[5]}$ The parent compound - as the Latin name indicates - is yellow. However, fulvene derivatives can be easily turned into orange, red or green colored dyes by respective substitution. Our method to generate a donor-acceptorsubstituted fulvene substructure made use of a combination of redox and Lewis acid catalysis. For both, the same tin(II) salt was employed which allowed to attach naphthoquinones 2 to a $C_{3}$ unit 
that was provided by donor-acceptor cyclopropane 1 (Scheme 1). ${ }^{[6][7]}$ In the presence of base and an oxidant, either oxygen from the air or $\mathrm{MnO}_{2}$, compounds of type $\mathbf{3}$ with a fulvene motif were generated.

The reaction cascade consisted of (i) the reduction of the naphthochinone $\mathbf{2}$ to the corresponding dianion which was generated by $\mathrm{Sn}^{\prime \prime}$. The donor-acceptor cyclopropane $\mathbf{1}$ is activated by the emerging $\mathrm{Sn}^{\mathrm{IV}}$ which enables the ring-opening by the nucleophilic attack of the dianion to form the substituted naphthochinone 4. An intramolecular Michael attack (ii) of the insitu generated malonate moiety to the electron-poor double bond of the naphthoquinone, (iii) deprotonation of an allylic hydrogen of intermediate 5, (iv) cleavage of a C-C bond by attack of an enolate to one of the methoxycarbonyl groups of $\mathbf{6}$, and $(v)$ further oxidation of $\mathbf{7}$ allowed access the fully conjugated system 3 . The method is compatible with different aryl substituents at the cyclopropane unit and several substituted naphthoquinone derivatives. The obtained products show a deep red color. In this paper, we describe the replacement of the hydroxy group at the central ring of the fulvene derivatives by a variety of carbon and heteroatom substituents and we report for the first time the preparation of a hexacyclic fulvene derivative by the use of an acenaphthalene-based donor-acceptor cyclopropane. The UVVis-NIR absorption properties of all the novel dyes with extended fulvene motifs were studied and selected examples were investigated by cyclic voltammetry and spectroelectrochemistry.

\section{Results and Discussion}

\section{Syntheses and UV-Vis Spectroscopy of New Dyes.}

Based on our previous work, we envisioned that the absorption of these fulvene-based dyes might be easily modified by substitution of the hydroxy group in the central ring of 3 . Therefore, the hydroxy group of 3a was converted into the corresponding triflate that should be a perfect leaving group even at an $s p^{2}$-hybridized carbon of the conjugated system. Indeed, we were able to react various nucleophiles with triflated $\mathbf{3 a}$. In all cases, an ipsosubstitution took place (Scheme 2). As a first group of nucleophiles we used a series of amines, primary and secondary, aromatic and aliphatic ones, to furnish the respective fulvene derivatives $3 \mathbf{b}-\mathbf{f}$ in $55-91 \%$ yields. Even ammonia was successfully employed affording the primary amine $\mathbf{3 g}$ in $82 \%$ yield.

Furthermore, several different anions were utilized to react with triflated $\mathbf{3 a}$. With the exception of fluoride, a smooth transformation was observed in all cases leading to derivatives $\mathbf{3 h}-\mathbf{m}$ in good yields. Halides such as chloride (3h), bromide (3i) and iodide $(\mathbf{3} \mathbf{j})$, but also thio- $(\mathbf{3 I})$ and selenocyanates $(3 \mathrm{~m})$ were successfully employed. The substitution reaction with phenolate afforded the anticipated aryl ether $\mathbf{3 k}$, a capricious compound, that tends to decompose to precursor $\mathbf{3 a}$. In addition, triflates are well established starting materials for palladium-catalyzed coupling reactions. These transformations had to be carried out in 1,2-dichloroethane since the triflates tend to decompose to the parent compound $\mathbf{3 a}$ in commonly used solvents such as THF or DMF. Nevertheless, the desired products $\mathbf{8 n}$ and $\mathbf{8 0}$, resulting from a Sonogashira and a Stille reaction, respectively, were obtained, albeit in rather modest yield.

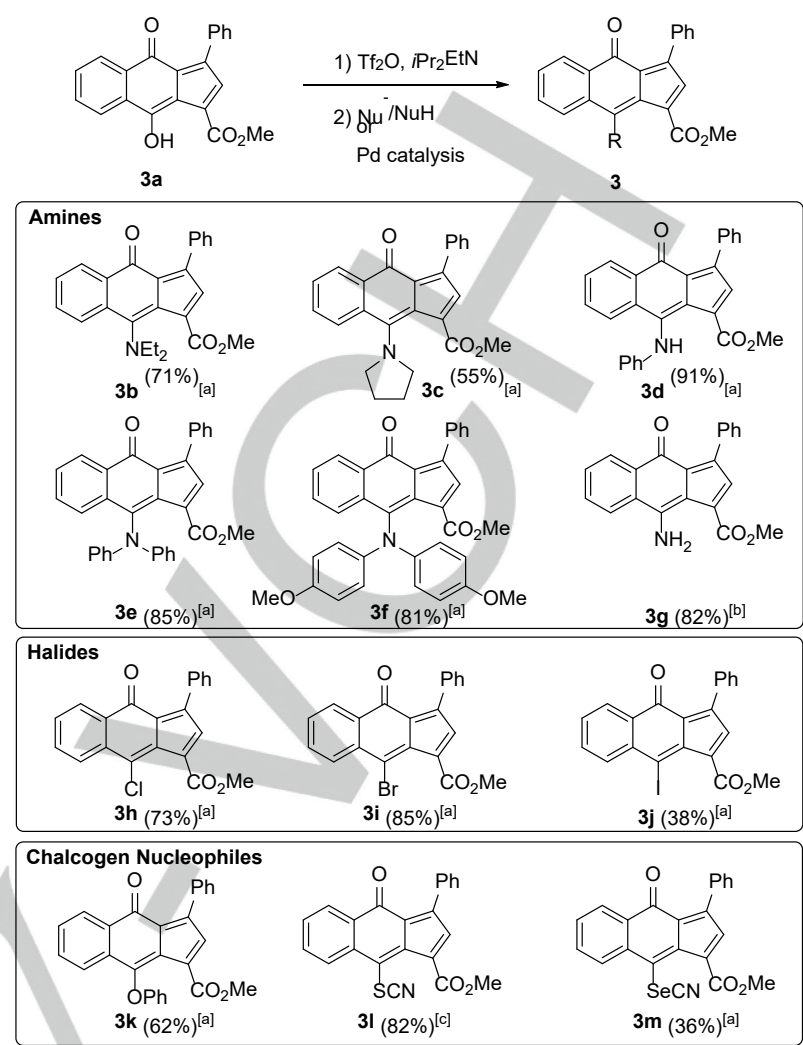

Carbon Substituents (via Pd catalysis)

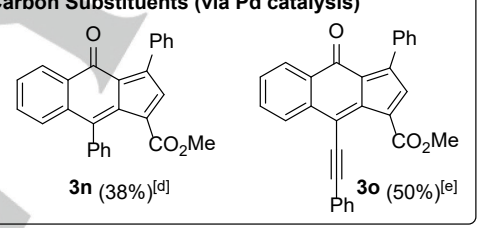

Scheme 2. Derivatisation of dye 3. [a] Reaction conditions: 1) 3 (1.0 equiv), (iPr) ${ }_{2} \mathrm{EtN}$ (3.0 equiv), $\mathrm{Tf}_{2} \mathrm{O}$ (2.5 equiv), $\mathrm{CH}_{2} \mathrm{Cl}_{2}(0.05 \mathrm{M}), 0{ }^{\circ} \mathrm{C}, 15 \mathrm{~min}$; filtration; 2) Nucleophile (3.0-5.0 equiv), $\mathrm{CH}_{2} \mathrm{Cl}_{2}(0.05 \mathrm{M}), 25^{\circ} \mathrm{C}$. [b] 2) $\mathrm{NH}_{4} \mathrm{Cl}$ (3.0 equiv), (iPr) ${ }_{2} \mathrm{EtN}$ (3.0 equiv), $25^{\circ} \mathrm{C}$. [c] 2) Nucleophile (3.0 equiv), 18-crown-6 (3.0 equiv), $\mathrm{CH}_{2} \mathrm{Cl}_{2} /$ acetonitrile $(1: 1,0.05 \mathrm{M}) ,40{ }^{\circ} \mathrm{C}$. [d] 2) $\mathrm{Pd}_{2}(\mathrm{dba})_{3}(5 \mathrm{~mol} \%)$, $\mathrm{PPh}_{3}$ (20 mol\%), CsF (2.2 equiv), $\mathrm{Ph}\left(\mathrm{CH}_{3}\right)_{3} \mathrm{Sn}$ (1.5 equiv), 1,2-dichloroethane (0.025 M), $100{ }^{\circ} \mathrm{C}$. [e] 2) $\mathrm{Pd}\left(\mathrm{PPh}_{3}\right)_{2} \mathrm{Cl}_{2}(10 \mathrm{~mol} \%)$, Cul $(50 \mathrm{~mol} \%),(i \mathrm{Pr})_{2} \mathrm{EtN}$ (1.5 equiv), phenylacetylene ( 0.6 equiv), 1,2 dichloroethane $(0.05 \mathrm{M}), 80^{\circ} \mathrm{C}$.

A change of the substituent at this specific position has a dramatic influence on the absorption properties in the visible range and thus results in a change of color of the compounds. Whereas the parent system with a hydroxy group as substituent (3a) shows a strong absorption at $\lambda_{\max }=497 \mathrm{~nm}$, more electronwithdrawing groups such as halides $(\mathbf{3 h}-\mathbf{j})$ and phenyl $(\mathbf{3 n})$ as substituent lead to an absorption at slightly shorter wavelengths (Table 1). Since we observe the complementary color such absorptions are associated with brighter red and orange compounds. A substitution with amines (compounds $\mathbf{3 b}-\mathbf{g}$ ) led to a red-shift of the absorption or in other words the HOMO is more raised in energy than the respective LUMO is effected. Whereas a pyrrolidine-substituent resulted in a purple compound 3c $\left(\lambda_{\max }=511 \mathrm{~nm}\right)$, the extension of the $\pi$-system by diphenyl or two 4-methoxyphenyl groups at the nitrogen even shifts the absorptions to $640-720 \mathrm{~nm}$ (3e and $\mathbf{3 f}$ ). 
Table 1. UV-Vis absorption and attenuation coefficients of $3 a-o$ in $\mathrm{CH}_{2} \mathrm{Cl}_{2}$ solution.

\begin{tabular}{|c|c|c|c|}
\hline Compound & $\mathbf{R}$ & $\lambda_{\max }[\mathbf{n m}]$ & $\varepsilon\left[10^{3} \mathrm{M}^{-1} \mathrm{~cm}^{-1}\right]$ \\
\hline $3 \mathrm{~h}$ & $\mathrm{Cl}$ & 457 & 12.0 \\
\hline $3 \mathbf{i}$ & $\mathrm{Br}$ & 459 & 13.8 \\
\hline $3 n$ & $\mathrm{Ph}$ & 460 & 10.7 \\
\hline $3 k$ & $\mathrm{OPh}$ & 463 & 5.9 \\
\hline $3 \mathbf{j}$ & I & 465 & 14.1 \\
\hline 31 & SCN & 487 & 14.8 \\
\hline 30 & $\mathrm{C} \equiv \mathrm{C}-\mathrm{Ph}$ & 496 & 14.4 \\
\hline $3 a$ & $\mathrm{OH}$ & 497 & 9.1 \\
\hline $3 m$ & $\mathrm{SeCN}$ & 497 & 15.1 \\
\hline $3 c$ & 1-Pyrrolidinyl & 511 & 10.2 \\
\hline $3 g$ & $\mathrm{NH}_{2}$ & 526 & 12.0 \\
\hline $3 b$ & $\mathrm{NEt}_{2}$ & 530 & 9.1 \\
\hline $3 d$ & $\mathrm{HNPh}$ & 568 & 10.7 \\
\hline $3 e$ & $\mathrm{NPh}_{2}$ & $640 ; 449$ & $7.6 ; 5.9$ \\
\hline $3 f$ & $\left(4-\mathrm{MeOC}_{6} \mathrm{H}_{4}\right)_{2} \mathrm{~N}$ & $719 ; 453$ & $11.0 ; 6.9$ \\
\hline
\end{tabular}

Furthermore, we were able to apply this methodology to enlarge the $\pi$-system by generation of a further six-membered ring containing two nitrogen atoms (Scheme 3). Therefore, compound 3a was triflated first and directly reacted with hydrazine or phenylhydrazine to form by condensation new heterocyclic products with a pyridazine subunit. The tautomer with a fully conjugated $\pi$-system is formed as unequivocally proved by $X$-ray crystallography of the $\mathrm{N}$-phenyl-substituted derivative $\mathbf{8 b}$. Only a weak absorption was observed for these species with crossconjugation; the $\lambda_{\max }$ values are much more blue shifted than the ones observed for compounds of type $\mathbf{3}\left(\mathbf{8} \mathbf{a}: \lambda_{\max }=379 \mathrm{~nm} ; \mathbf{8 b}\right.$ : $\lambda_{\max }=420 / 500 \mathrm{~nm}$ ).

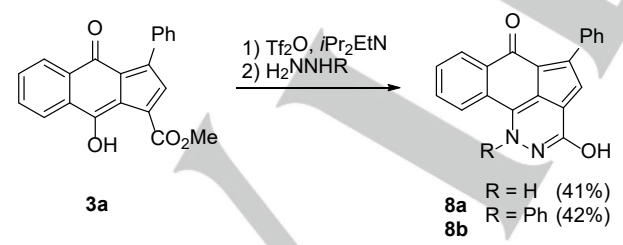

Scheme 3. Enlargement of the $\pi$-system by reaction with hydrazine derivatives leading to compounds $\mathbf{8 a}$ and $\mathbf{8 b}$ with an annulated pyridazine moiety.

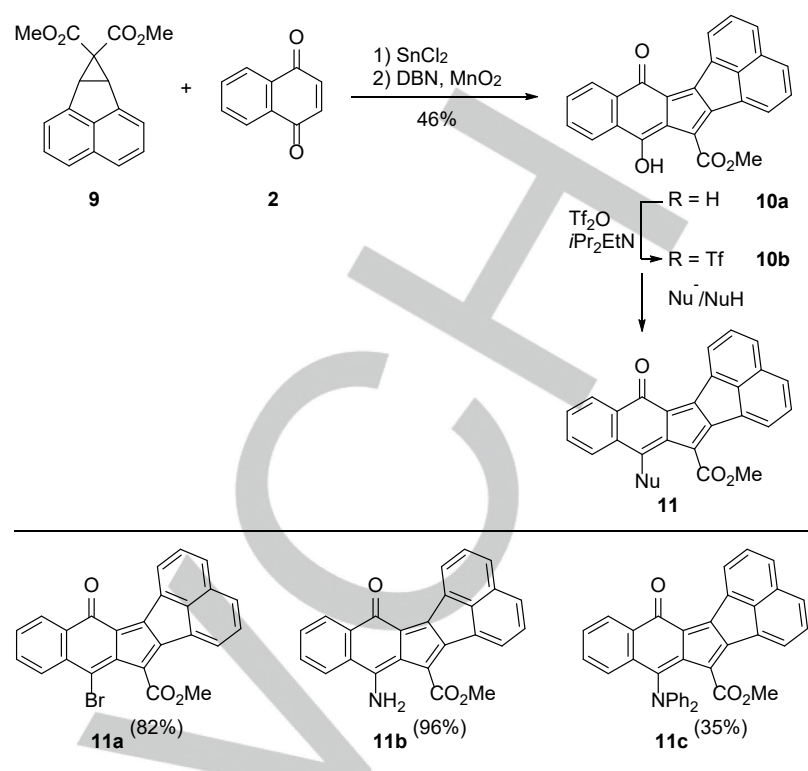

Scheme 4. Preparation of hexacyclic dyes 11a-c starting from acenaphthalenebased D-A cyclopropane 9

With these results in hand, we aimed to expand the aromatic system in the carbon backbone of the dye by using donoracceptor cyclopropane $\mathbf{9}$ which is easily obtained by cyclopropanation of acenaphthalene. Considering the recent high activity in the field of D-A cyclopropanes it is surprising that this interesting type has been neglected so far. The transformation was conducted in an analogous manner as described above to afford compound 10a in $46 \%$ yield (Scheme 4 ). The structure of the hexacyclic compound 10a was confirmed by X-ray crystallography. As expected, the extension of the $\pi$-system deepened its color and a dark purple dye was obtained $\left(\lambda_{\max }=\right.$ $517 \mathrm{~nm}$ ). Moreover, also the color of the compound 10a with the extended carbon backbone was easily changed simply by substitution of the hydroxy group. By the procedure mentioned above we prepared the respective triflate $10 \mathrm{~b}$ and converted it into the bromo compound 11a $\left(\lambda_{\max }=490 \mathrm{~nm}\right)$, the primary amine 11b $\left(\lambda_{\max }=552 \mathrm{~nm}\right)$ and the tertiary amine 11c $\left(\lambda_{\max }=647 \mathrm{~nm}\right)$.

The structures of compounds $\mathbf{3 g}, \mathbf{8 b}$, and $10 \mathbf{a}$ were elucidated by $\mathrm{X}$-ray analysis. In structure $\mathbf{3 g}$ the bond length of C1-C2, C2-C3 and C1-C9A are very similar ranging from 1.394$1.418 \AA$. A clear-cut single-double bond alternance as the fulvene structure suggests and as it is found in many other crystal structures of fulvenes is not observed. The co-planarity of ester and amine with the $\pi$-system is further stabilized by a hydrogen bridge of the amino hydrogen to $\mathrm{O} 2$. In structure $\mathbf{8 b}$ with a further annulated nitrogen-containing ring the fulvene-type substructure is even less pronounced. The formal $\mathrm{C}-\mathrm{C}$ double bond $\mathrm{C} 1-\mathrm{C} 9 \mathrm{~A}$ is with $1.442 \AA$ much longer than the formal $\mathrm{C}-\mathrm{C}$ single bond $\mathrm{C} 1-\mathrm{C} 2$ $(1.400 \AA)$. The plane of the $N$-phenyl substituent is tilted by $82^{\circ}$ to the plane of the pyridazine unit. In contrast, the bond lengths of the fulvene subunit in the enlarged system 10a are in agreement with the Lewis structure. The $\mathrm{C}-\mathrm{C}$ double bonds between $\mathrm{C} 1-\mathrm{C}$ A $(1.382 \AA)$ and $\mathrm{C} 2-\mathrm{C} 3(1.387 \AA)$ are much shorter than the C-C single bond $\mathrm{C} 1-\mathrm{C} 2$ with $1.452 \AA$. The hydroxyl group and $\mathrm{O} 2$ at the carbonyl group form a hydrogen bond (cp. compound $\mathbf{3 g}$ ). 


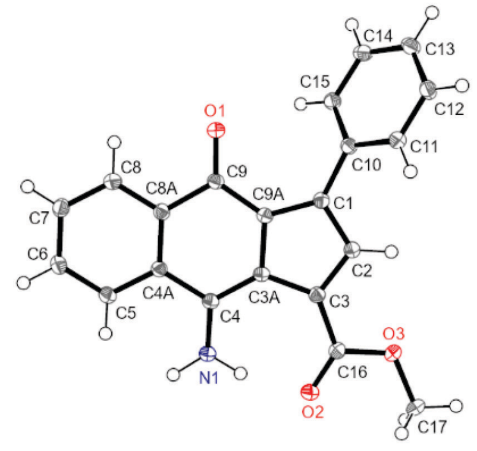

$3 g$

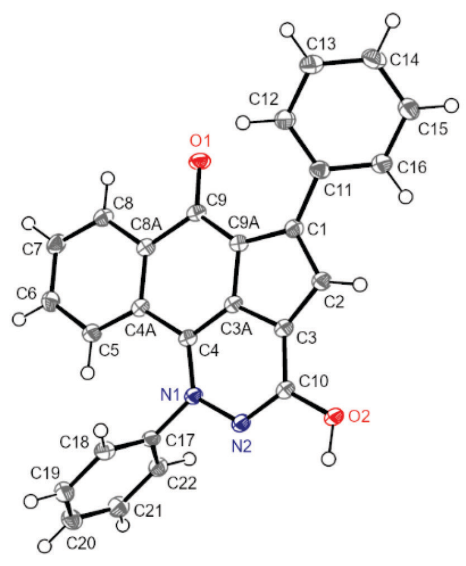

$8 b$

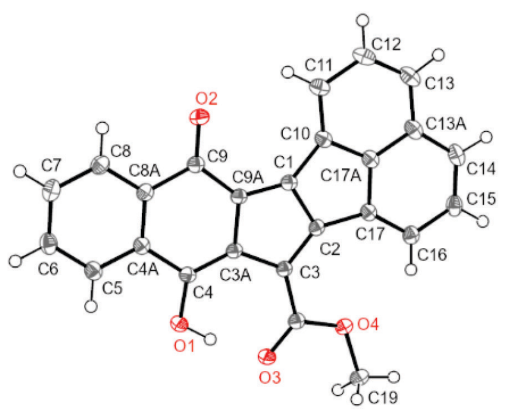

$10 a$

Figure 1. Molecular structures (ORTEP plots) of $\mathbf{3 g}$ (top), $\mathbf{8} \mathbf{b}$ (middle) and $\mathbf{1 0 a}$ (bottom) in the solid state. ${ }^{[8]}$

\section{Spectroelectrochemical Investigations.}

Given the ubiquitous utilization of quinoid compounds as redox mediators, the electrochemical properties of these new chromophores are of special interest. The redox potentials of selected compounds were determined by means of cyclic voltammetry in $0.1 \mathrm{M} \mathrm{NBu} \mathrm{PF}_{6} / \mathrm{CH}_{2} \mathrm{Cl}_{2}$ solution and a glassy carbon working electrode. The compounds $\mathbf{3 a}, \mathbf{3} \mathbf{j}$ and $10 \mathbf{a}$ show one irreversible oxidation and two reduction processes of which the first one shows a varying degree of reversibility for the respective compounds (see Supporting Information for peak current ratios). Multiple re-oxidation events after reduction at shifted potentials are indicating follow-up chemical reactions. In order to rationalize the electrochemical responses representative examples of the broad substrate scope have been chosen. Besides the parent compound $\mathbf{3 a}(\mathrm{R}=\mathrm{OH})$ also the iodo- $(\mathbf{3 j}(\mathrm{R}=$ I)), amino- (3d $(R=N H P h))$ and alkynyl-substituted (3o $(R=$ $\mathrm{CCPh})$ ) derivatives were investigated. In addition, one example of the $\pi$-system being extended with the naphthalene moiety was studied (10a).

The reductive electrochemical responses are depicted in Figure 2. As can be easily seen from the relationship between structure and electrochemical response the follow-up reactions seem to be caused by the protic $\mathrm{OH}$ or $\mathrm{NH}$ moieties, respectively. ${ }^{[9]}$ In the case of the iodo substituent, the well-known dehalogenation aryl/alkyl halides may easily occur at sufficiently cathodic potentials. ${ }^{[10]}$ Interestingly, the first reduction becomes almost completely reversible if measured alone, indicating the formation a relatively stable radical anion, which is probably due to the high degree of delocalization. For the parent compound $\mathbf{3 a}$, the influence of the solvent was also investigated. Interestingly, this compound seems to react with acetonitrile as a solvent upon reduction, whereas the $\mathrm{CV}$ in $\mathrm{CH}_{2} \mathrm{Cl}_{2}$ shows less peaks, which are more reversible. Given the relatively high degree of reversibility for 3a and 3o, we resorted to spectroelectrochemical measurements in order to elucidate the site of reduction and chemical reversibility. measured in $0.1 \mathrm{M} \mathrm{NBu}_{4} \mathrm{PF}_{6} / \mathrm{CH}_{2} \mathrm{Cl}_{2}$ with a glassy carbon working electrode.

These results will be discussed for $\mathbf{3 0}$, since hydroxylated congener 3a showed an almost completely irreversible response in the spectroelectrochemical timescale (Figure 3 and Supporting Information). Surprisingly, the middle UV part of the light source seems to trigger a reaction, which leads to irreversible spectroelectrochemistry. If only the near UV part is used $(>300$ $\mathrm{nm}$ ) no change in the spectrum is observed upon irradiation of the compound (see Figure S26 in the Supporting Information). During reduction the band at $498 \mathrm{~nm}$ decreases in intensity whereas we observed new bands at 406, 574 and $785 \mathrm{~nm}$. The band with a 
maximum at $785 \mathrm{~nm}$ is significant as it ranges well into the NIR region. This band is only observed for the anion radical form of the compound and not for the neutral or the dianionic form, thus displaying the potential of this compound to act as NIR electrochromic dyes. Our initial assessment that the optical properties can be modulated by substitution of the hydroxyl moiety are also backed by a full TD-DFT calculation, which reveal electron donation of the phenyl substituent and the fulvene motif itself, based on the difference densities for the transition at 497 $\mathrm{nm}$ for 3a and $498 \mathrm{~nm}$ for $\mathbf{3 o}$ at the PBE0/def2-TZVP level of theory (see Table S20 and Table S22 in the Supporting Information). As expected, the hydroxy, the carbonyl and the methoxycarbonyl moieties act as electron acceptors upon electronic excitation. Upon re-oxidation of either the radical anion or the dianion we regain only a part (around $60 \%$ ) on the initial band at $498 \mathrm{~nm}$ of the native compound, which indicates only partial (electro)chemical reversibility on the spectroelectrochemical timescale. This has already been indicated by the peak current ratios for compound 3o (see Supporting Information). What can clearly be seen from the measurement of $\mathbf{3 a}$ is that the spectrum is not reversible, which is a consequence of the longer timescale of the spectroelectrochemical experiment, which requires slower scan rates in order to achieve a quantitative conversion of the electroactive species.

From the CV measurement at the same scan rate it can already be seen that the redox events become electrochemically irreversible (see Supporting Information). Given the multiple reoxidation waves that appear after reductions it is conceivable that major molecular rearrangements take place, that result in a compound that has another redox potential as the native species and are re-oxidized at a different potential.

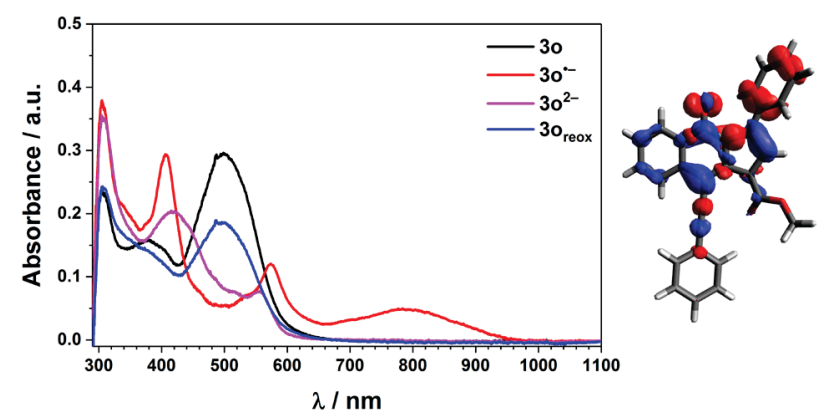

Figure 3. OTTLE-spectroelectrochemistry of 30 measured in $0.1 \mathrm{M} \mathrm{NBu}_{4} \mathrm{PF}_{6}$ $\mathrm{CH}_{2} \mathrm{Cl}_{2}$ with a gold working electrode. Right: Electron difference density plot for the transition at $550 \mathrm{~nm}$ (iso-surface value of 0.004 ) which corresponds to the HOMO-LUMO transition.

In order to further probe the structure of the anion radical and dianion radical EPR spectroelectrochemistry was employed. For 3a and 3o EPR spectra have been recorded, which both display a g-value of 2.003 and did not show any resolved hyperfine splitting, which is probably due to the strong delocalisation of the system as predicted by the spin population analysis (Figure 4) which would lead to unfavorable line-width to hyperfine coupling ratios.

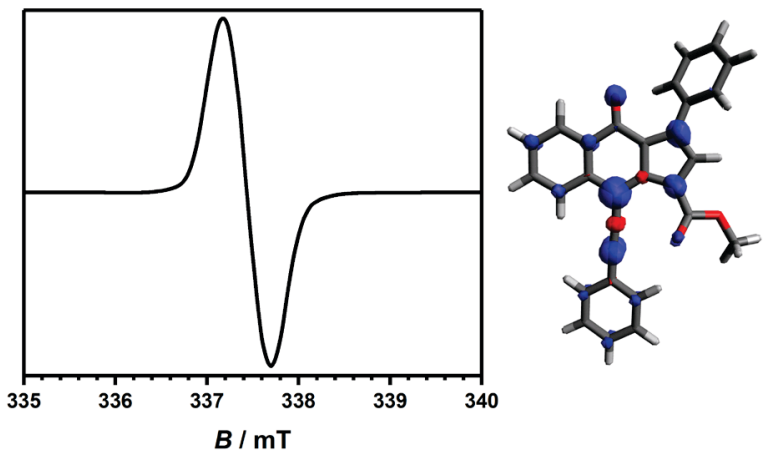

Figure 4. EPR spectroelectrochemistry of 30 measured in $0.1 \mathrm{M} \mathrm{NBu}_{4} \mathrm{PF}_{6} /$ $\mathrm{CH}_{2} \mathrm{Cl}_{2}$ with a g-value of 2.003. Right: Spin density (iso-surface value of 0.005 ) for 3o, for numerical values see Supporting Information.

\section{Conclusion}

We have developed a protocol to synthesize a library of dyes with an embedded fulvene moiety by using the unique reactivity of donor-acceptor cyclopropanes. The absorptions of the compounds were easily shifted to longer wavelengths by substitution of the emerging hydroxy group attached to the central ring of the fulvene motif. Triflation of the latter paved the way to a facile substitution at an $\mathrm{sp}^{2}$-hybridized carbon. Furthermore, we accessed a tetracyclic structure incorporating the fulvene substructure and an annulated pyridazine unit by the reaction with hydrazine derivatives. The synthesis of a new donor-acceptor cyclopropane based on acenaphthalene led to an expansion of the carbon backbone which was associated with a further red shift in the absorption. In addition, we have demonstrated that the absorption properties of these dyes, their reduction potentials as well as the reversibility of the redox processes can be easily tuned by a judicious selection of substituents. Their electronic properties in the various redox states have further been investigated by a combination of UV-Vis-NIR/EPR spectroelectrochemistry and (TD)-DFT calculations. We have also demonstrated the first signs of NIR electrochromism in these dyes. Owing to the synthetic tunability, and the versatile properties of these systems, they and related compounds might be potentially useful as redox mediators, or as electrochromic dyes.

\section{Acknowledgements}

This research was supported by the European Research Council (ERC Consolidator Grant "GAINBYSTRAIN" to D.B.W.). The high-performance computing facilities at ZEDAT, FU Berlin, are kindly acknowledged for access to computing resources.

Keywords: donor-acceptor cyclopropanes $\bullet$ fulvene $\bullet$ dyes $\bullet$ spectroelectrochemistry $\cdot$ EPR spectroscopy

[1] Y. Saikawa, K. Hashimoto, M. Nakata, M. Yoshihara, K. Nagai, M. Ida, T Komiya, Nature 2004, 429, 363

[2] O. R. Luca, R. H. Crabtree, Chem. Soc. Rev. 2013, 42, 1440. 
[3] a) R. J. Mortimer, Compr. Coord. Chem. 2004, 9, 581; b) M. D. Ward, J. Solid State Electrochem. 2005, 9, 778; c) W. Kaim, A. Klein, Eds, Spectroelectrochemistry, Royal Society of Chemistry, 2008; d) W. Kaim, J. Fiedler, Chem. Soc. Rev. 2009, 38, 3373; e) W. Kaim, Coord. Chem. Rev. 2011, 255, 2503; f) W. Polit T. Exner, E. Wuttke, R. F. Winter, Bioinorg. React. Mech. 2012, 8, 85.

[4] A. Lücht, L. J. Patalag, A. U. Augustin, P. G. Jones, D. B. Werz, Angew. Chem. Int. Ed. 2017, 56, 10587

[5] a) J. H. Day, Chem. Rev. 1953, 53, 167; b) K. Hafner, K. H. Häfner, C. König, M. Kreuder, G. Ploss, G. Schulz, E. Sturm, K. H. Vöpel, Angew. Chem. Int. Ed. Engl. 1963, 2, 123; c) E. D. Bergmann, Chem. Rev. 1968, 68, 41; d) E. Aqad, P. Leriche, G. Mabon, A. Gorgues, V. Khodorkovsky, Org. Lett. 2001, 3, 2329; e) A. J. Peloquin, R. L. Stone, S. E. Avila, E. R. Rudico, C. B. Horn, K. A. Gardner, D. W. Ball, J. E. B. Johnson, S. T. lacono, G. J. Balaich, J. Org. Chem. 2012, 77, 6371; f) E. Shurdha, B. K. Repasy, H. A. Miller, K. Dees, S. T. lacono, D. W. Ball, G. J. Balaich, RSC Adv. 2014, 4, 41989

[6] Reviews: a) H.-U. Reissig, R. Zimmer, Chem. Rev. 2003, 103, 1151; b) M. Yu, B. L. Pagenkopf, Tetrahedron 2005, 61, 321; c) C. A. Carson, M. A. Kerr, Chem. Soc. Rev. 2009, 38, 3051; d) F. De Simone, J. Waser, Synthesis 2009, 2009, 3353; e) M. A. Cavitt, L. H. Phun, S. France, Chem Soc. Rev. 2014, 43, 804; f) T. F. Schneider, J. Kaschel, D. B. Werz, Angew. Chem. Int. Ed. 2014, 53, 5504; g) H. K. Grover, M. R. Emmett, M. A. Kerr, Org. Biomol. Chem. 2015, 13, 655; h) R. A. Novikov, Y. V. Tomilov, Mendeleev Commun. 2015, 25, 1

[7] a) Y. Xia, X. Liu, H. Zheng, L. Lin, X. Feng, Angew. Chem. Int. Ed. 2015, 54, 227; b) D. D. Borisov, R. A. Novikov, Y. V. Tomilov, Angew. Chem. Int. Ed. 2016, 55, 12233; c) T. Chidley, N. Vemula, C. A. Carson, M. A. Kerr, B. L. Pagenkopf, Org. Lett. 2016, 18, 2922; d) L. K. B. Garve, M. Pawliczek, J. Wallbaum, P. G. Jones, D. B. Werz, Chem. Eur. J. 2016, 22, 521; e) L. K. B. Garve, M. Petzold, P. G. Jones, D. B. Werz, Org. Lett. 2016, 18, 564; f) A. Ghosh, S. Mandal, P. K. Chattaraj, P. Banerjee, Org. Lett. 2016, 18, 4940; g) T. Kaicharla, T. Roy, M. Thangaraj, R. G. Gonnade, A. T. Biju, Angew. Chem. Int. Ed. 2016, 55, 10061; h) S. Racine
B. Hegedus, R. Scopelliti, J. Waser, Chem. Eur. J. 2016, 22, 11997; i) J Sabbatani, N. Maulide, Angew. Chem. Int. Ed. 2016, 55, 6780; j) J Wallbaum, L. K. B. Garve, P. G. Jones, D. B. Werz, Chem. Eur. J. 2016, 22, 18756; k) D.-C. Wang, M.-S. Xie, H.-M. Guo, G.-R. Qu, M.-C. Zhang, S.-L. You, Angew. Chem. Int. Ed. 2016, 55, 14111; I) Y. Xia, L. Lin, F. Chang, Y. Liao, X. Liu, X. Feng, Angew. Chem. Int. Ed. 2016, 55, 12228; m) A. U. Augustin, M. Sensse, P. G. Jones, D. B. Werz, Angew. Chem. Int. Ed. 2017, 56, 14293; n) S. Das, C. G. Daniliuc, A. Studer, Angew Chem. Int. Ed. 2017, 56, 11554; o) R. Dey, P. Banerjee, Org. Lett. 2017, 19, 304; p) L. K. B. Garve, P. G. Jones, D. B. Werz, Angew. Chem. Int Ed. 2017, 56, 9226; q) L. K. B. Garve, A. Kreft, P. G. Jones, D. B. Werz, J. Org. Chem. 2017, 82, 9235; r) J. Preindl, S. Chakrabarty, J. Waser Chem. Sci. 2017, 8, 7112; s) J. Wallbaum, L. K. B. Garve, P. G. Jones, D. B. Werz, Org. Lett. 2017, 19, 98; t) A. O. Chagarovskiy, V. S. Vasin, V. V. Kuznetsov, O. A. Ivanova, V. B. Rybakov, A. N. Shumsky, N. N. Makhova, I. V. Trushkov, Angew. Chem. Int. Ed. 2018, 57, 10338; u) S. Das, C. G. Daniliuc, A. Studer, Angew. Chem. Int. Ed. 2018, 57, 4053; v) A. Kreft, P. G. Jones, D. B. Werz, Org. Lett. 2018, 20, 2059; w) D. Perrotta, M.-M. Wang, J. Waser, Angew. Chem. Int. Ed. 2018, 57, 5120; x) B. M. Trost, W.-J. Bai, C. Hohn, Y. Bai, J. J. Cregg, J. Am. Chem. Soc. 2018 , 140,6710 .

[8] CCDC contain the supplementary crystallographic data for this paper These data are provided free of charge by The Cambridge Crystallographic Data Centre.

[9] O. A. Levitskiy, D. A. Dulov, O. M. Nikitin, A. V. Bogdanov, D. B. Eremin, K. A. Paseshnichenko, T. V. Magdesieva, ChemElectroChem 2018, 5, 3391.

[10] a) A. A. Isse, G. Berzi, L. Falciola, M. Rossi, P. R. Mussini, A. Gennaro J Appl Electrochem 2009, 39, 2217; b) A. Gennaro, A. A. Isse, P. R. Mussini in Organic electrochemistry (Eds.: O. Hammerich, B. Speiser), CRC Press, Boca Raton, London, New York, 2016, pp. 917-940; c) Dennis G. Peters in Organic electrochemistry (Eds.: O. Hammerich, B. Speiser), CRC Press, Boca Raton, London, New York, 2016, pp. 941 980.

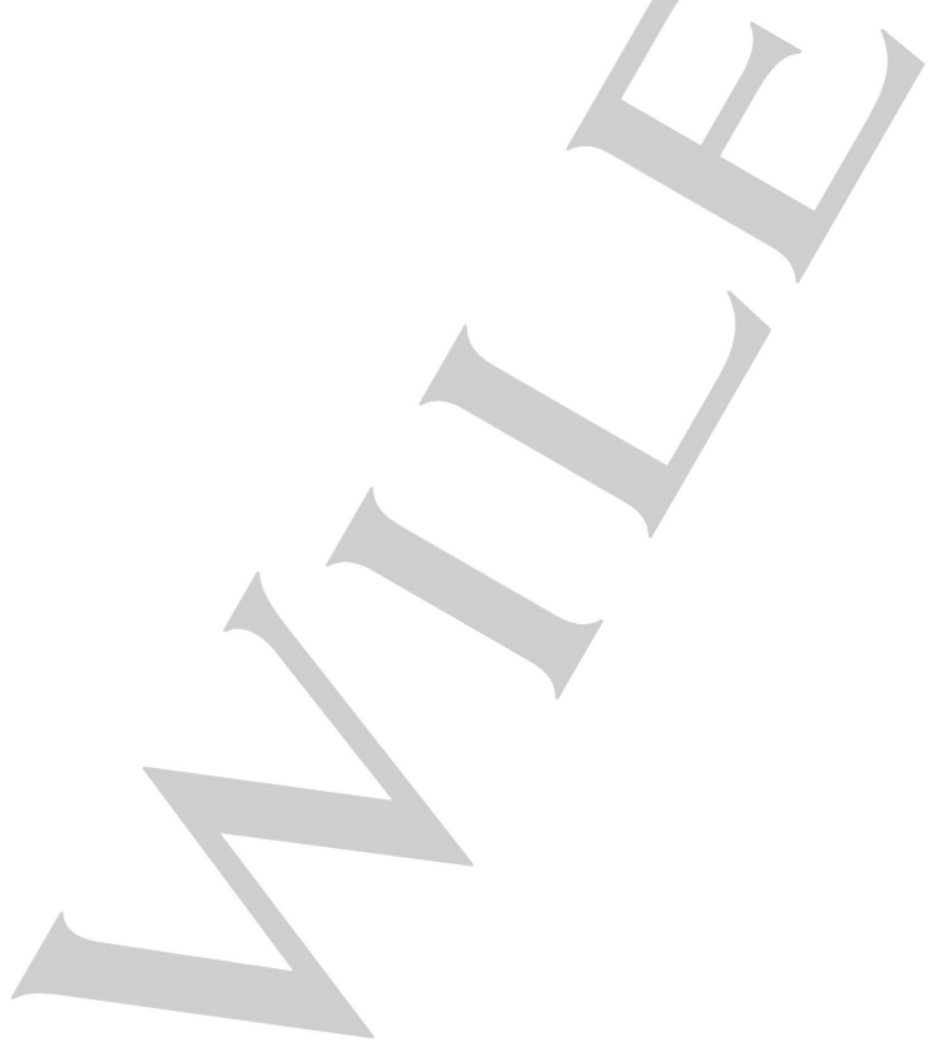




\section{Full Paper}

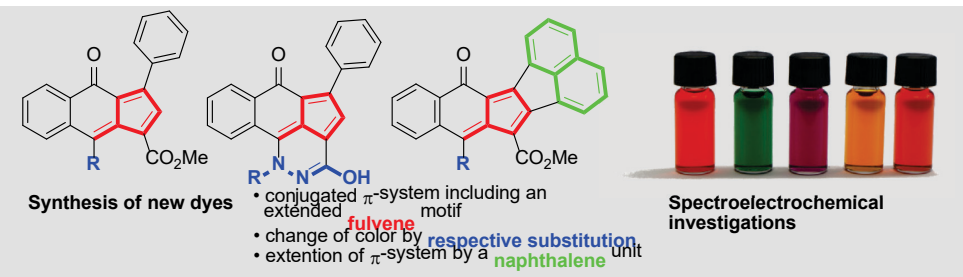

Novel fulvene dyes: A simple approach to synthesize dyes containing a fulvene subunit by using D-A cyclopropane chemistry and subsequent substitution reactions is presented. The color, reduction potentials and reversibility of the redox processes are controlled by the choice of only one substituent. A novel D-A cyclopropane leads to extended $\pi$-systems with a naphthalene unit.
Alexander Lücht, Sebastian Sobottka, Lukas J. Patalag, Peter G. Jones, Hans-Ulrich Reissig, Biprajit Sarkar, * and Daniel B. Werz

Page No. - Page No.

Novel Dyes Based on Extended

Fulvene Motifs: Synthesis via Redox

Reactions of Naphthoquinones with Donor-Acceptor Cyclopropanes and Their Spectroelectrochemical Behavior 